\title{
SIGNIFICAÇÕES DE COORDENADORES PEDAGÓGICOS ACERCA DA FORMAÇÃO CONTÍNUA DE PROFESSORES: análise a partir da Psicologia Sócio-Histórica
}

\author{
MEANINGS OF PEDAGOGICAL COORDINATORS ABOUT CONTINUOUS \\ TRAINING OF TEACHERS: analysis from Socio-Historical Psychology
}

\author{
SIGNIFICACIONES DE LOS COORDINADORES PEDAGÓGICOS SOBRE LA \\ FORMACIÓN CONTINUA DE LOS PROFESORES: análisis desde la \\ Psicología Sociohistórica
}

Cristiane De Sousa Moura TeIXEIRA (iDa

\section{Resumo}

Neste artigo, discutimos as significações produzidas por coordenadores pedagógicos acerca da formação contínua de professores, considerando que no atual momento histórico essa é a atividade principal a ser desenvolvida por estes profissionais na escola. Para isto, fundamentamo-nos na Psicologia Sócio-Histórica, sobretudo, nas ideias de Vigotski $(2007,2009,2010)$ sobre significado e sentido, considerando ainda as categorias mediação e historicidade. Os dados aqui analisados foram produzidos em sessão reflexiva realizada com três coordenadoras pedagógicas que trabalham em diferentes escolas públicas. Os dados produzidos foram analisados por meio do procedimento denominado Núcleos de significação (AGUIAR; OZELLA, 2013), o qual possibilita apreender o sujeito por meio das significações que são produzidas por ele. A análise dos dados evidenciou que as significações em processo de desenvolvimento acerca da formação contínua são mediadas por perspectivas de formação centradas sobretudo nas dimensões técnicas e práticas, as quais não concebem coordenadores pedagógicos e professores como seres multideterminados. Revelam ainda a necessidade de investir em processos formativos que evidenciem as contradições sociais, econômicas e políticas que determinam as relações sociais.

Palavras-chave: Coordenação Pedagógica. Significado e Sentido. Formação Contínua de Professores. Psicologia Sócio-Histórica

\footnotetext{
a Universidade Federal do Piauí - UFPI, Teresina, Piauí, Brasil. Doutora em Educação. E-mail: cristianeteixeira@ufpi.edu.br.http://orcid.org/0000-0001-9259-1802

Rev. Caminhos da Educação: diálogos, culturas e diversidades, Teresina, v. 1, n. 3, p. 166-187, set./dez. 2019
} 


\section{Abstract}

In this article, we discuss the meanings produced by pedagogical coordinators about the continuous training of teachers, considering that in the current historical moment this is the main activity to be developed by these professionals at school. For this, we are based on Socio-Historical Psychology, above all, on the ideas of Vigotski $(2007,2009,2010)$ about meaning and sense, also considering the categories mediation and historicity. The data analyzed here were produced in a reflective session held with three pedagogical coordinators who work in different public schools. The data produced were analyzed using the procedure called Nuclei of meanings (AGUIAR; OZELLA, 2013), which makes it possible to apprehend the subject through the meanings that are produced by him. The analysis of the data showed that the meanings in the development process about continuous training are mediated by training perspectives focused mainly on technical and practical dimensions, which do not conceive pedagogical coordinators and teachers as multidetermined beings. They also reveal the need to invest in training processes that highlight the social, economic and political contradictions that determine social relations.

Keywords: Pedagogical Coordination. Meaning and Sense. Continuous Training of Teachers. Socio-Historical Psychology

\section{Resumen}

En este artículo, discutimos los significados producidos por los coordinadores pedagógicos sobre la formación continua de los profesores, teniendo en cuenta que, en el momento histórico actual, esta es la actividad principal que deben desarrollar estos profesionales en la escuela. Para esto, nos basamos en la Psicología Sociohistórica, sobre todo, en las ideas de Vigotski $(2007,2009,2010)$ sobre el significado y el sentido, considerando también las categorías mediación e historicidad. Los datos analizados aquí se produjeron en una sesión reflexiva celebrada con tres coordinadores pedagógicos que trabajan en diferentes escuelas públicas. Los datos producidos fueran analizados con la ayuda del procedimiento denominado Núcleos de Significado (AGUIAR; OZELLA, 2006, 2013), que permite aprehender al sujeto a través de los significados que él produce. El análisis de los datos mostró que los significados en el proceso de desarrollo sobre la formación continua están mediados por perspectivas de formación centradas principalmente en dimensiones técnicas y prácticas, que no conciben a los coordinadores pedagógicos y a los docentes como seres multideterminados. También revelan la necesidad de invertir en procesos de capacitación que resalten las contradicciones sociales, económicas y políticas que determinan las relaciones sociales.

Palabras clave: Coordinación Pedagógica. Significado y Sentido. Formación Continua de Profesores. Psicología Sociohistórica

\section{Introdução}


A tese marxista de que o trabalho é o fundamento da humanidade consiste na ideia primordial que orienta a proposição de Vigotski (2009), de que o ser humano resulta do desenvolvimento histórico social. Tais ideias são igualmente importantes para compreendermos como os indivíduos se constituem, uma vez que qualquer explicação que não tenha como base o homem situado no contexto histórico social não explica o homem real.

Por trabalho, entendemos uma forma de relação entre o homem e a natureza, na qual, esta última tem sua forma alterada em razão da ação intencional do homem sobre ela; logo, tanto a natureza quanto o ser humano são transformados durante a atividade de trabalho. É somente, por meio desta compreensão de trabalho que podemos explicar a história humana, como sendo o processo de transformação do ser natural em ser social.

Mas, o que podemos afirmar sobre a atividade que os educadores de um modo geral realizam? Seria trabalho? Mas não transformam a natureza! Assim, como o trabalho a educação também é uma especificidade humana e seu surgimento está relacionada ao fato de que o homem não nasce pronto, nessa medida, a educação se torna necessária como meio de garantir ao homem a sua segunda natureza, como afirma Saviani (1984). Isto é, diferentemente dos outros animais, nem tudo, no homem, está garantido pela natureza e, portanto, precisa ser produzido historicamente sobre a base na natureza biofísica. Ou seja, sobre a base da natureza biofísica se produz ideias, valores, atitudes, conhecimentos, símbolos. E que atividade humana possibilita essa produção? A educação. Logo, esta consiste conforme o autor, no "ato de produzir, direta e intencionalmente, em cada indivíduo singular, a humanidade que é produzida histórica e coletivamente pelo conjunto dos homens" (SAVIANI, 1984, p 02). Disto depreendemos que a produção do humano decorre do trabalho, seja daquele que visa produzir a própria subsistência material dos homens, como daquele que não produz a subsistência material, mas que produz no homem a sua segunda natureza.

Mas, ora esses dois processos de produção não ocorrem de forma dissociados um do outro. 0 próprio processo de produzir determinado produto material está contido aí um determinado conhecimento, afinal para transformar a natureza essa precisa ser compreendida pelo homem, o que significa conhecer suas propriedades, sua regularidade e seus processos de mudança. Assim, ao apropriar-se da natureza, o homem produz conhecimento e, por conseguinte, desenvolve o que Vigotski (2009) denominou de funções psicológicas superiores, como por exemplo: as significações, conceitos, símbolos, 
cálculo. Vigotski (2009) fundamentado na filosofia de Marx e Engels (2006) explicou que estas funções resultam da atividade especificamente humana, trabalho, portanto elas se formam no âmbito social e são internalizadas, isto é, tornam-se individuais.

Essas reflexões nos orientam a algumas afirmações: a primeira, de que os coordenadores pedagógicos possuem, assim como a profissão que realizam, processualidade histórica; os coordenadores pedagógicos e realidade social se constituem mutuamente como tais na realização do trabalho no espaço escolar, mediados pelas condições sociais, o que significa dizer que ao trabalhar, os coordenadores pedagógicos produzem a si mesmos ao tempo que produzem a realidade social.

Autores como, Christov (2002), André e Dias (2010), Almeida, Placco e Souza (2011), indicam que este profissional é o articulador dos processos formativos que ocorrem na escola. Mas nem sempre esse profissional foi assim compreendido. Historicamente, os coordenadores pedagógicos estiveram associados às ações de controle e regulação do trabalho docente. Esse aspecto tem gênese na própria inserção do profissional no espaço escolar. Segundo Nogueira (2000) na década de 1960, quando a denominação ainda era supervisor escolar, este profissional foi instalado na escola num contexto marcado por política educacional determinada pelas questões econômicas e políticas. A fonte de inspiração para as políticas educacionais naquele cenário histórico, estava na indústria e, neste setor havia o supervisor de produção que tinha o claro propósito de controlar a produção dos trabalhadores, assim como, regular o comportamento deste. Ao supervisor escolar, revestido sob o discurso de modernidade, cabia o controle sobre o trabalho do professor, sobretudo, do ponto de vista ideológico. Esse é um atributo que ainda não foi superado pelo coordenador pedagógico.

Evidenciamos então, que no trabalho deste profissional o velho, ainda contido no novo, mantém com este uma luta incessante, a qual provoca rupturas e continuidades na história dessa profissão. Refletindo sobre isso, debruçamo-nos em pesquisa em curso de Doutorado em Educação visando explicar as significações dos coordenadores acerca do trabalho que realizam na escola, sobretudo, aquele relacionado à formação contínua de professores, por ser esta atividade atribuída a ele.

A significação, é para Vigotski (2009), uma generalização, que reflete de modo completamente distinto a realidade na consciência, são, portanto, construções intelectivas abstratas que refletem a realidade objetiva com suas contradições. Neste sentido, encontramos razão para entendermos que, por meio das significações, isto é, dos significados e sentidos desenvolvidas pelos coordenadores pedagógicos acerca da formação 
contínua de professores podemos compreender o trabalho destes profissionais no contexto da escola pública, já que por meio delas é possível evidenciar determinadas zonas do real.

Neste artigo objetivamos apresentar parte dos resultados que foram obtidos por tal pesquisa e, para isso, organizamos o artigo da seguinte forma: na seção seguinte, apresentamos os procedimentos metodológicos para produção e análise dos dados e, em seguida analisamos os resultados da investigação, considerando os pressupostos teóricos da Psicologia Sócio-Histórica e a perspectiva crítica de formação contínua que defendemos.

\section{Aportes teórico-metodológicos para compreender as significações dos coordenadores pedagógicos}

O objetivo desta seção é discutir os pressupostos teórico-metodológicos assentados na Psicologia Sócio-Histórica, assim como, os princípios teóricometodológicos que nortearam a pesquisa empírica. Para isso, organizamos a seção de modo a discutir inicialmente as categorias e na sequência os princípios, ambos teóricometodológicos.

Vigotski (2009), ao buscar compreender a relação entre pensamento e linguagem subverte toda a lógica desenvolvida até então nas pesquisas sobre o assunto, uma vez que seus estudos revelam que o significado da palavra se encontra na interseção entre o pensamento e a palavra; é, portanto, a unidade de análise indecomponível e pertence a ambos os processos (pensamento e linguagem). "É um traço constitutivo indispensável da palavra. É a própria palavra vista no seu aspecto interior" (VIGOTSKI, 2009, p. 398).

As categorias Significado e Sentido, compõem um par dialético e, portanto, não podem ser compreendidas de forma dicotomizada. E, ainda, é preciso considerá-las como atividades da consciência que se constituem no próprio desenvolvimento histórico da consciência humana. Ressaltamos que a linguagem é concebida como aspecto constituidor do sujeito, pois tem importância central, evidenciando-a não apenas como um sistema linguístico, mas, sobretudo, destacando seu aspecto psicológico que se revela na relação pensamento e linguagem. A linguagem é fator primordial para o desenvolvimento das funções psicológicas superiores do sujeito, já que ela por se encontrar na base da consciência é responsável pela função de organizar e planejar o pensamento. Ao ser elemento organizador e planejador do pensamento, a linguagem 
também participa de forma decisiva para a desenvolvimento da consciência humana, já que a consciência individual se forma e se desenvolve a partir das relações que mantemos com os outros e com a realidade social.

Vigotski (2009, p. 398) explica que o significado é ao mesmo tempo fenômeno do pensamento e da linguagem. Como fenômeno do pensamento, o significado possui toda generalização, já que a palavra nunca se refere a um objeto de forma isolada, mas a uma classe de objetos. É neste sentido que o pensamento se relaciona com a palavra e é nela materializada. Como fenômeno da linguagem, o significado está relacionado ao pensamento e direcionado por ele. Podemos então afirmar que o significado da palavra é fenômeno que vai do pensamento à palavra e da palavra ao pensamento. 0 significado é, portanto, uma unidade do pensamento verbalizado, pois se apresenta como pensamento e linguagem concomitantemente.

Feitos os esclarecimentos podemos então explicar que por significado Vigotski (2009) entende que estes são produções históricas, sociais, relativamente estáveis e, por serem compartilhadas, são eles que permitem a comunicação e a socialização das experiências entre os homens. Os significados são os conteúdos instituídos mais fixos, compartilhados, que são apropriados pelos sujeitos e subjetivizado. Além disso, "são fundamentais para a constituição do psiquismo" (AGUIAR et. al., 2009, p. 61). Ao passo que, para Vigotski (2009, p. 465),

[...] o sentido da palavra é a soma de todos os fatos psicológicos que ela desperta em nossa consciência. Assim, o sentido é sempre uma formação dinâmica, fluida, complexa, que tem várias zonas de estabilidade variada. 0 significado é apenas uma dessas zonas do sentido que a palavra adquire no contexto de algum discurso e, ademais, uma zona mais estável, uniforme e exata.

O sentido é, portanto, mais amplo que o significado, porque consiste em uma das zonas de sentido, a mais estável e fixa. Conforme explica Vigotski (2005, p.181): "o significado dicionarizado de uma palavra nada mais é do que uma pedra no edifício do sentido, não passa de uma potencialidade que se realiza de formas diversas na fala".

Com base nestas ideias afirmamos que as significações produzidas pelos coordenadores pedagógicos sobre seu trabalho se constituem ao longo da história vivida por eles; é o que melhor expressa sua subjetividade, pois é constituída de história e de contradições. Assim, o entendemos que o sentido se refere à totalidade do sujeito histórico e à sua condição vital. Discutir sentido significa discutir também a subjetividade, é trazer para a discussão o coordenador pedagógico como sujeito concreto, histórico, singular; não diluído.

Assim, nosso propósito ao definir os caminhos que seriam trilhados na pesquisa 
empírica foi a de ultrapassar a realidade aparente e trazer à tona a explicação da realidade como totalidade concreta e, para isso foi necessário refletirmos acerca de determinados princípios norteadores da pesquisa fundamentada na Psicologia Sócio-Histórica. Vigotski (2007) assevera a necessidade de as pesquisas voltar-se para o processo de desenvolvimento do fenômeno e não para objetos fixos. Esse é o primeiro princípio: analisar processos e não produtos. No caso, nosso objetivo é explicar o processo de produção das significações dos coordenadores pedagógicos acerca da formação contínua de professores e, para isso, é necessário considerar que tais significações não se encontram fixas, prontas e imutáveis, mas em processo de desenvolvimento o qual é mediado pela realidade social. Contudo, a explicação do atual estágio de desenvolvimento destes significados só pode ser alcançada retornando à sua gênese.

A busca pela gênese significa compreender o coordenador pedagógico e seu trabalho em seu movimento e processo de mudança. Aqui se revela o valor heurístico da categoria Historicidade. É ela quem nos permite compreender o fenômeno investigado para além da aparência, do imediato, e, portanto, evidenciando o processo. Conforme afirma Lukács (1979, p. 79),

A historicidade implica não o simples movimento, mas também e sempre uma determinada direção na mudança, uma direção que se expressa em transformações quantitativas de determinados complexos, tanto em si quanto em relação com outros componentes.

O segundo princípio destacado por Vigotski (2007) é a explicação versus descrição. Enquanto a descrição limita-se à aparência da realidade, a explicação penetra na intimidade do objeto. Aqui, vale enfatizarmos o que Marx (apud VIGOTSKI, 2007, p. 66) afirma: "[...] se a essência dos objetos coincidisse com a forma de suas manifestações externas, então toda ciência seria supérflua". Para explicar o processo de produção das significações acerca da formação contínua de professores, o pesquisador precisa apreender as mediações históricas que constituem o processo.

As mediações revelam que a relação entre o homem e o mundo não é uma relação direta, mas uma relação mediada. Disto, perguntamos, no que consiste essa mediação? Para Marx e Engels (2006), as mediações são as expressões históricas das relações que o homem edificou com a natureza e, consequentemente, das relações sociais daí decorrentes, nas várias formações humanas que a história registrou. Ela é que permite compreender as múltiplas determinações que constituem a realidade social e, de modo particular, o trabalho dos coordenadores pedagógicos. 
O valor heurístico da categoria de mediação consiste em possibilitar explicar a relação entre os processos histórico-sociais e os processos individuais mentais internalizados pelo ser humano. Isto significa que ao se analisar um determinado aspecto do real esta análise não pode se desvincular dos processos históricos sociais e quem garante essa não desvinculação é a categoria de mediação.

O terceiro e último princípio evidenciado por Vigotski (2007) é o problema do comportamento fossilizado. Ou seja, são processos que passaram através de estágio bastante longo de desenvolvimento histórico e se fossilizaram" (VIGOTSKI, 2007, p. 67). Em outras palavras, há comportamento que aparentemente perderam sua essência, tornandose automatizados, mecânicos e, portanto, tornam-se difíceis de serem explicados.

Nas palavras de Vigotski (2007, p. 67), estes processos "perderam sua aparência original, e sua aparência externa nada nos diz sobre sua natureza interna". Quando isso ocorre, Vigotski (2007) alerta que a única de forma de penetrar na natureza interna do objeto investigado é por meio de sua gênese. 0 autor explica ainda que o encontro da gênese com a forma fossilizada do objeto une o passado ao presente tendo a história como mediadora. Disto podemos depreender que este princípio nos esclarece que as significações que se desenvolveram durante um longo período histórico é o final da linha e, por meio da qual podemos unir o passado e o presente, ou ainda, como Vigotski (2008, p. 68) informa, une "os estágios superiores do desenvolvimento aos estágios primários".

Considerando os princípios acima explicitados passamos a descrever de modo sucinto os procedimentos metodológicos que foram utilizados na realização da pesquisa. Destacaremos como os dados foram produzidos e analisados. Utilizamos como procedimento para produção de dados a sessão reflexiva coletiva em razão de esta proporcionar relação de interação entre pesquisador e pesquisados. Assim, realizamos duas sessões reflexivas coletivas com três coordenadoras pedagógicas que trabalham em escolas da rede pública estadual na cidade de Teresina (PI) e, que aqui foram denominadas de Margarida, Rosa e Flora. 0 objetivo das sessões reflexivas foi dialogar com as partícipes sobre o trabalho que elas desenvolvem na escola e, de modo particular, sobre o processo de formação contínua junto aos professores.

No desenvolvimento da sessão reflexiva coletiva optamos por seguir os passos da reflexão crítica proposto por Smyth (1992), conforme sistematização de Liberalli (2010). Smyth (1992) explica como se desenvolve a atividade de reflexão crítica, considerando as quatro formas de ação. Estas quatro formas consistem em descrever, informar, confrontar e reconstruir.

Descrever consiste na etapa mais elementar; revela a percepção que temos sobre a atividade que realizamos, mas quando o coordenador pedagógico passa a Rev. Caminhos da Educação: diálogos, culturas e diversidades, Teresina, v. 1, n. 3, p. 166-187, set./dez. 2019 
estabelecer relações daquilo que realizou com as teorias, ele consegue extrapolar da descrição para a informação, assim, esta etapa exige que ele fundamente suas ações nas teorias que oferecem sustentação a elas. Na terceira etapa, o coordenador pedagógico avança na sua reflexão ao se questionar sobre os propósitos de sua atividade, sobre a contribuição social que oferece, sobre os interesses que envolvem determinadas ações realizadas por ele. Passa então a ser capaz de refletir sobre as ideologias que permeiam seu trabalho, sobre as relações de poder presentes entre os homens e suas atividades; sua reflexão vai além do que simplesmente faz entre os muros da escola e segue na direção mais ampla dos vínculos da escola com o social. Ao pensar sobre seu trabalho nesta dimensão mais ampla é possível que o coordenador pedagógico planeje a reconstrução de seu fazer, passa então a recriar e esta recriação torna-se necessidade em razão de novo modo de pensar o que foi elaborado.

Assim, a sessão reflexiva coletiva cumpre o objetivo não apenas de produzir dados, mas, sobretudo, tem o propósito de se constituir como espaço formativo para pesquisador e pesquisados, uma vez que pelo processo de reflexão é possível produzir novas significações acerca do trabalho do coordenador pedagógico.

Mas, ressaltamos que embora nosso propósito com esta técnica seja a de provocar nos coordenadores pedagógicos processo de produção de novas significações, nem sempre este objetivo se cumpre tal qual o desejo do pesquisador, pois neste movimento o pesquisador não está sozinho, mas está em relação com o outro e, como qualquer relação social ela está sujeita às condições comuns de toda interação social. Além disso, não podemos deixar de considerar as significações fossilizadas, cristalizadas, difíceis de superar. Com isto estamos afirmando que nem sempre a transformação desejada pelo pesquisador acontece, o que não significa que a pesquisa não foi válida, mas sim, evidencia a realidade vivenciada pelo sujeito em sua totalidade concreta, mediado pelas contradições.

Para analisar os dados utilizamos a proposta metodológica denominada Núcleos de Significação (AGUIAR; OZELLA, 2013) que consiste nas seguintes etapas: leitura recorrente dos dados produzidos objetivando familiarização e apropriação dos conteúdos presentes nos dados. Esta familiarização com o conteúdo dos dados permite seleção dos pré-indicadores, isto é, os vários temas presentes no material analisado, bem como a frequência destes, sejam por repetição ou reiteração, pela importância enfatizada na fala dos sujeitos; seja pela carga emocional que evidenciam, pela ambivalência ou contradições ou ainda, pelas insinuações não concretizadas. Na sequência da análise, os pré-indicadores são então articulados em indicadores considerando os critérios da 
similaridade, complementaridade ou contraposição, os quais são aglutinados entre sim para construção dos núcleos de significação.

No processo de análise empregando esse procedimento metodológico iniciamos pela seleção dos pré-indicadores, os quais foram articulados em dois indicadores: Formação é aperfeiçoamento constante por meio da troca de experiências e Formação para desenvolvimento profissional e pessoal. A articulação destes indicadores permitiu chegarmos ao núcleo de significação denominado: 'O 'faz-tudo' na escola significa a formação contínua ora como aperfeiçoamento, ora desenvolvimento profissional".

0 processo de levantamento dos pré-indicadores, a aglutinação dos indicadores e a constituição do núcleo de significação nos permite apreender algumas significações presentes na fala das coordenadoras que nos ajudam a compreender as múltiplas determinações que envolvem o trabalho desse profissional como articulador dos processos de formação contínua de professores no contexto da escola pública.

O indicador primeiro denominado: Formação é aperfeiçoamento constante por meio da troca de experiências, se evidencia como as coordenadoras pedagógicas investigadas entendem por formação, quem realiza e de que modo a formação contínua acontece na escola. No segundo indicador denominado: Formação para desenvolvimento profissional e pessoal, destacamos o para que serve a formação contínua de acordo com as coordenadoras pedagógicas investigadas.

\section{Formação contínua de professores: aperfeiçoamento ou desenvolvimento profissional?}

A constituição deste núcleo evidencia como as coordenadoras investigadas significam o processo de formação contínua de professores na escola. Os sentidos que elas atribuem à formação não consistem em reflexos de estímulos externos, tão pouco, são oriundas de suas características inatas, mas entendemos que o modo como Flora Rosa e Margarida compreende o processo de formação contínua na escola é uma construção sócio-histórica a partir de processo de internalização dos significados sociais atribuídos à formação contínua.

Historicamente formação contínua foi compreendida como aperfeiçoamento, capacitação, atualização, reciclagem, os quais são termos que segundo Marin (1995) carregam a ideia da imperfeição, da incapacidade, da necessidade de atualizar e, portanto, a formação contínua preencheria as lacunas, ou imperfeições deixadas pela formação inicial. Entendem que oferecendo informações atualizadas, ou aperfeiçoando práticas, 
estes cursos serão capazes de produzir novos conhecimentos e mudanças nas formas de agir de professores e coordenadores pedagógicos.

Para Flora formação contínua é aperfeiçoamento, aquisição, qualificação e melhoria do trabalho. Entendemos que esta forma de compreender a formação contínua pode ter sido desenvolvida por meio das experiências formativas que a coordenadora tem vivenciado, uma vez que, no contexto educacional vigorou durante muito tempo o significado social de formação contínua como aperfeiçoamento do trabalho dos professores.

A pesquisa realizada por Davis, Nunes e Almeida (2011, p. 66) sobre formação contínua evidencia em seus resultados "que as políticas de formação continuada de grande parte das Secretarias de Educação investigadas estão centradas em práticas consideradas 'clássicas' (CANDAU, 1997), ou seja, cursos preparados por especialistas para aprimorar os saberes e as práticas docentes". Podemos ainda, acrescentar que as políticas de formação contínua empreendidas pelas secretarias de educação que se fundamentam nos modelos clássicos, assim o fazem porque partem da ideia de que a formação inicial não foi suficiente, ou não conseguiu efetivar aprendizagens consideradas, pelas secretarias, como importantes para a realização da profissão docente. Esta constatação também é confirmada pela pesquisa de Davis, Nunes e Almeida (2011, p. 56). As autoras afirmam, a partir de seus resultados que "de maneira geral, as Secretarias de Educação investigadas partem do pressuposto de que a formação inicial dos docentes é precária".

Assim, inferimos que Flora por vivenciar cursos de formação contínua promovidos pela secretaria de educação tem internalizado esse significado social que é compartilhado por quem se insere neste espaço. Aspecto que pode ser percebido quando Flora afirma que, formação "é um momento de estudo em que você procura se aperfeiçoar, qualificar em determinadas ações que você já faz no dia a dia, ou seja, o sentido atribuído à formação contínua por Flora é de buscar a perfeição no trabalho que realiza, o que demonstra o valor que ela atribui ao trabalho. Mas também, formação é "querer adquirir mais informações e informações novas, diferente daquelas que você já tem e, aperfeiçoar aquelas que você já possui". Este sentido não se distância da ideia de aperfeiçoamento, mas o complementa, pois para Flora são as informações novas que possibilitam o aperfeiçoamento do trabalho que realiza.

Rosa tem produzido significações acerca da formação contínua que não são distintos das significações de Flora. Embora Rosa admita que tenha dificuldade para definir formação contínua, ela considera que esta se refere aos cursos feitos para Rev. Caminhos da Educação: diálogos, culturas e diversidades, Teresina, v. 1, n. 3, p. 166-187, set./dez. 2019 
melhorar a formação acadêmica e, pontua, destacando os cursos que os professores fazem como segunda graduação, as especializações, mestrado. Ou seja, Rosa, significa a escola como espaço de atuação e a academia como espaço de formação e, portanto, de produção de conhecimento. A significação que Rosa produz acerca da formação contínua, também se vincula às perspectivas de formação contínua considerada clássica, pois não vê o espaço da escola como espaço ao mesmo tempo de trabalho de formação para os trabalhadores. Para esta coordenadora, a formação contínua está situada fora da escola.

Porém, a coordenadora Rosa, também considera que existe formação no dia a dia e que esta exige "esperteza pra que ele enxergue além dos olhos [...] e sabedoria [a mesma de como] Cristo trabalhou com as pessoas, por meio de parábolas". 0 sentido de formação como sabedoria cristã revela os valores e crenças da coordenadora pedagógica e, possivelmente, consiste em determinação para o trabalho que realiza. Esse sentido que Rosa atribui não se vincula necessariamente ao desenvolvimento do professor como profissional, mas sim, ao aspecto humano que é imprescindível a qualquer profissional.

Ainda sobre como as coordenadoras pedagógicas investigadas compreendem a formação contínua, Margarida evidencia três aspectos bastantes presentes na literatura que discute esta modalidade de formação. Para Margarida, formação é processo contínuo, pois sempre há o que aprender, mas é, também, troca de experiências que pode acontecer a todo o momento e ainda considera que a quantidade de cursos implica na qualidade.

Neste sentido, vale destacar o que Libâneo (2004, p. 227) afirma sobre formação contínua de professores. Para este autor, "formação continuada é o prolongamento da formação inicial visando ao aperfeiçoamento profissional teórico e prático no próprio contexto de atuação e ao desenvolvimento de uma cultura geral mais ampla, para o exercício profissional". Isto significa que embora para o autor a formação vise ao aperfeiçoamento, esta deve acontecer no contexto de atuação. Assim, o significado para formação contínua que o autor atribui, destaca a escola como o espaço privilegiado em que esta formação deve acontecer.

Esteves e Rodrigues (1993, p. 44-45), destacam a importância de a formação contínua ser qualitativamente diferenciada em relação à formação inicial, já que ela ocorre após o profissional estar inserido na carreira docente e perdurar ao longo de toda carreira profissional,

[...] formação contínua será aquela que tem lugar ao longo da carreira profissional após a aquisição da certificação profissional inicial (a qual só tem lugar após a conclusão da formação em serviço) privilegiando a ideia de que a sua inserção na carreira docente é qualitativamente diferenciada em relação à formação inicial, independentemente do momento e do tempo de serviço docente que o professor já possui quando faz a sua 
profissionalização, a qual consideramos ainda como uma etapa de formação inicial. (1993, pp. 44-45).

Ao afirmar que "a gente percebe que tudo que se faz hoje tem que ser em termos de formação e essa formação é até com o aluno", Margarida considera que a formação contínua não está descolada da rotina da escola, mas a escola é compreendida como espaço educativo. Libâneo (2004) nos ajuda a entender melhor o sentido de formação atribuído por Margarida à formação contínua. 0 autor considera que quando a gestão da escola se insere na perspectiva sociocrítica, a escola é vista como espaço educativo, o que significa dizer que o modo como as pessoas trabalham são entendidas como práticas educativas, já que transmitem valores, atitudes, modos de agir e, isso, no entendimento de Libâneo (2004), implica em aprendizagem para professores e alunos.

Margarida ainda considera que a formação é troca de experiências quando afirma que: "a gente ver muito o professor estar junto com o outro ali um repassando, experiência, então é uma coisa muito importante...". Esta fala da coordenadora expressa a valorização do saber da experiência, o que nos orienta a pensar que para ela o saber que se constrói no próprio exercício da profissão tem um valor diferenciado em relação ao saber oriundo da academia. A valorização do saber da experiência ganhou destaque a partir de estudos e das publicações de Maurice Tardif (2002). Suas investigações partiram dos saberes dos professores, sua natureza e origem e, considera que estes saberes tem grande valor para a profissão docente, pois tem origem no trabalho cotidiano e no conhecimento que os docentes desenvolvem sobre o meio. Estes saberes surgem da experiência profissional e, esta mesma quem os torna válido. São, então, incorporados e se traduzem nas habilidades do saber fazer e do saber ser. Vale ressaltar que os saberes produzidos na experiência profissional permitem aos docentes julgar a formação inicial.

Portanto, para Margarida, a formação como troca de experiência entre os professores confere à experiência e, portanto, à prática a legitimidade para o trabalho que o docente realiza. Entretanto, chamamos a atenção para o fato de que não é o tempo de serviço ou de experiência do professor que determina a produção de saberes, mas sim, a reflexão crítica que ele desenvolve sobre essa prática, pois do contrário, o que temos não é o compartilhamento de saberes, e sim a reprodução reiterativa de um saber fazer que não cede lugar à criação do novo.

Ainda há que se destacar o valor que Margarida atribui à quantidade de cursos de formação como critério para garantir qualidade no trabalho do professor. Sobre este aspecto Nóvoa (1995, p. 25) é enfático ao afirmar que "a formação não se constrói por 
acumulação (de cursos, de conhecimentos ou de técnicas), mas sim através de uma atuação de reflexividade crítica sobre as práticas e de (re)construção permanente de uma identidade pessoal".

Podemos compreender que a origem da valorização da quantidade de cursos em detrimento da qualidade, que Margarida ressalta, pode estar associada à intensificação do trabalho docente. É, ainda, em Nóvoa (1995) que nos apoiamos para entender essa relação. Para o autor, a intensificação do trabalho docente, e, por conseguinte, dos coordenadores pedagógicos, entre outras coisas, contribui para que a qualidade ceda lugar à quantidade, isto é, passamos a realizar mais ações, mas sem nos preocuparmos com a qualidade do que está sendo feito. Isto nos orienta a pensar que recebemos mais atribuições, precisamos também de mais cursos que nos permitam realizar todas as ações que nos são atribuídas.

O indicador em discussão além de evidenciar o que é formação para as coordenadoras, também evidenciou quem é responsável por esta formação. De acordo com Flora "todos nós somos agente formadores dos outros, porque em cada contato que você tem com outro você está passando e recebendo conhecimentos". Sendo a escola o locus de formação contínua dos professores, podemos, então, entender que sob este aspecto todos na escola, de fato, tornam-se formadores uns dos outros por meio da troca de experiências. É neste sentido que compreendemos que a formação contínua que se desenvolve por meio da troca de experiências constitui a cultura docente em ação (CANADU, 1997).

Ao considerar que todos na escola são formadores, Flora evidencia a importância de que a formação esteja integrada no dia a dia do trabalho dos professores, que trabalhar e formar não sejam atividades distintas. Este sentido é complementado por Margarida quando ela esclarece que trabalhando na escola a formação acontece constantemente, ou seja, "no momento que está havendo um planejamento ou mesmo entre os próprios professores ali trocando ideias é uma formação". Ou ainda, a formação na qual você ensina e aprende melhora o trabalho na escola é evidenciado quando Margarida afirma: "eu acho que dentro da escola a gente está constantemente em formação às vezes até no papo na hora do recreio você tem ideias belíssimas para o trabalho que vai fazer." e, ainda, ao afirmar que "na formação você tanto aprende como você pode ensinar também" a coordenadora destaca que está constantemente ensinando, porque forma os outros e aprendendo, porque forma a si mesmo. Sobre este aspecto, é importante destacarmos que Nóvoa (1995, p. 26) considera que "o diálogo entre os professores é fundamental para consolidar saberes emergentes da prática profissional".

Rev. Caminhos da Educação: diálogos, culturas e diversidades, Teresina, v. 1, n. 3, p. 166-187, set./dez. 2019 
As falas de Margarida são reveladoras do sentido atribuído à escola por esta coordenadora. Para ela, a escola não é lugar em que só os alunos aprendem e os professores ensinam, mas é o lugar onde os professores ao compartilharem os seus saberes produzidos pela experiência tornam-se formadores uns dos outros e, assim aprendem a desenvolver a própria profissão. A escola é considerada uma realidade singular que possui história, cultura e identidade únicas, já que nela os professores e coordenadores vivenciam a dinâmica escolar e aprendem a profissão compartilhando os saberes entre si.

Aprender a profissão no próprio espaço de trabalho produzindo e compartilhando conhecimentos é para Nóvoa (1995, p. 25) "investir na pessoa e dar um estatuto ao saber da experiência". Para nós, é desenvolvimento.

Desse modo, o segundo indicador denominado Formação para desenvolvimento profissional e pessoal explica para que serve a formação contínua. Para Flora a formação deve proporcionar também o desenvolvimento do profissional como pessoa. Sobre isso Flora expressa: "um ponto que eu considero essencial que a gente deve considerar é a questão do lado pessoal também, porque não adianta eu querer melhorar só o meu lado profissional se eu não melhorar o meu lado pessoal, que a formação ela tem que interferir também no meu pessoal".

De fato, Flora tem razão, a formação visa não só ao profissional, mas também o pessoal, afinal, como diz Nóvoa (1995, p. 25) "o professor é uma pessoa. E uma parte importante da pessoa é o professor". Isto significa que os processos formativos voltados para os professores devem produzir a vida dos professores.

Ao expressar como compreende o processo de formação contínua, Flora chama a atenção para a importância da dimensão pessoal como bem destacou Nóvoa (1995). Ao evidenciar esta dimensão a coordenadora demonstra compreender que o desenvolvimento do professor não se dá apenas no campo da produção de conhecimentos, mas visa também, produzir a vida dos professores, como eles pensam, sentem. Compreendemos que a formação contínua de professores é potencializadora do desenvolvimento profissional e envolve a dimensão pessoal, considerando que esta dimensão se refere às ao desenvolvimento do professor no que diz respeito às questões éticas, políticas, cognitivas e afetivas. Isto demonstra a preocupação da coordenadora com as atitudes dos professores que podem ser desenvolvidas por meio de processos formativos.

Para Rosa, formação é crescimento profissional (sistematizada e escolarizada) e pessoal (não sistematizada e que ocorre por meio de troca de experiência no dia a dia). 
Assim, expressa Rosa: "Porque tem uma formação sistematizada que é essa acadêmica que você frequenta todos os níveis e vai conseguindo seus títulos e tem a formação enquanto pessoa, enquanto gente, transformando suas maneiras, suas atitudes, seu jeito de ser que eu acredito que na escola acontece muito essa transformação das atitudes, o ser humano, de procurar ser mais humano".

Ao significar a formação como crescimento profissional e pessoal, Rosa diferencia estas duas dimensões que a formação contínua visa atender. Para a coordenadora, a dimensão profissional é desenvolvida quando ocorre de modo sistematizado e escolarizado, ao passo que a dimensão pessoal, ocorre de modo assistemático, por meio da troca de experiências. Somos, então, orientados a pensar que para Rosa, desenvolvimento profissional e pessoal situam-se em campos opostos e não articulados como parte de um mesmo processo.

Entretanto, é preciso seguir para além das significações reveladas pelas coordenadoras pedagógicas. Urge se contrapor a toda forma de perspectiva de formação contínua que concebe o coordenador pedagógico ou o professor como profissional técnico (perspectiva do profissional técnico), ao qual, cabe seguir procedimentos racionais determinados pela ciência e, portanto, agir de forma instrumental, sem a reflexão necessária acerca dos determinantes que medeiam o seu trabalho. Ou ainda, perspectivas de formação contínua que concebe estes profissionais descolados da realidade social mais ampla. Esta última perspectiva parte do pressuposto de que os coordenadores pedagógicos e, também, os professores podem por meio da reflexão acerca de sua prática resolver os problemas existentes na escola (perspectiva do profissional prático). Esquecem que a escola é um complexo que se constitui mediada pelas múltiplas determinações histórica-sociais e que os problemas que nela existem, consistem em reflexos da realidade social mais ampla.

No entanto, há de se considerar igualmente relevante destacar o caráter assistemático da formação contínua realizada na escola. A significação de que basta estar em interação com outros trocando experiências não é suficiente para considerar um processo formativo, isto porque tais interações não são realizadas de forma consciente acerca da intencionalidade que toda atividade humana, sobretudo, aquelas que visam a formação do ser humano precisa perquirir. Ou seja, práticas cotidianas de trocas de experiências não expressam a relação entre os objetivos (intencionalidade de atividade) e os meios necessários para atingi-la. Logo, sem intencionalidade da direção qualquer resultado parece satisfatório.

No nosso entendimento, tais perspectivas de formação, assim como as significações que as coordenadoras pedagógicas investigadas revelam negam o conhecimento à classe Rev. Caminhos da Educação: diálogos, culturas e diversidades, Teresina, v. 1, n. 3, p. 166-187, set./dez. 2019 
dos profissionais da educação, uma vez que subtraem dos docentes os objetos de seu trabalho. Ou seja, os professores quando formados nestas perspectivas não se apropriam dos conceitos fundamentais do seu trabalho, assim como, também, não se apropriam das metodologias, das escolhas acerca dos instrumentos, dos modos de avaliação da aprendizagem. A educação em geral e de modo particular, a formação contínua não precisa ser útil para o imediato, o que significa desconsiderar o conhecimento científico. A consequência é o empobrecimento do processo de humanização tanto do coordenador pedagógico como do professor.

A formação contínua necessária precisa fundamentar-se em referenciais que concebem a formação do professor como promotora do conhecimento de si e de suas relações de mediação como o outro e com a realidade social. A formação contínua de professores, nesse caso, deixa de ser reduzida à função meramente instrumental ou prática para se constituir em condição essencial para o desenvolvimento de profissionais da educação emancipados, autônomos e conscientes da responsabilidade social, ética e política que lhes cabe na construção da sociedade.

\section{Considerações finais}

As significações produzidas pelas coordenadoras pedagógicas investigadas acerca da formação contínua vão ao encontro dos significados socialmente produzidos e compartilhados no contexto educacional, o que revela que as coordenadoras são diretamente afetadas pelos discursos vigentes acerca dessa modalidade de processo formativo. Ao expressarem sobre os sentidos que atribuem à formação contínua de professores evidenciam também como veem significando o espaço da escola, especialmente, para Margarida, a escola é espaço de trabalho e ao mesmo tempo espaço em que as pessoas se formam em interação, por meio de saberes produzidos na experiência profissional.

Em síntese podemos apontar que as significações sobre formação contínua produzida pelas coordenadoras evidenciam dois aspectos importantes: A escola como locus de formação contínua de professores, a valorização dos saberes produzidos na experiência docente e o desenvolvimento do profissional docente.

A análise deste núcleo evidenciou várias zonas de sentido em processo de produção, as quais sintetizamos que para Rosa, Flora e Margarida, a formação contínua é aperfeiçoamento constante que se dá por meio da troca de experiências visando o desenvolvimento profissional e pessoal dos professores. Além disso, as categorias 
historicidade, sentido e significado nos permitiram compreender o movimento de produção destas significações, ou seja, os sentidos que as coordenadoras atribuem à formação contínua tem processualidade história e dimensão social, já que encontra nexo nos significados compartilhados no contexto educacional.

Entretanto, se quisermos efetivar formação contínua de professores que ajudem tanto coordenadores pedagógicos como professores a realizar seu trabalhando visando o desenvolvimento humano, o que em outras palavras significa a superação de determinadas perspectivas de formação, precisamos investir em processos formativos que evidenciem as contradições sociais, econômicas e políticas que determinam as relações sociais.

\section{Referências}

AGUIAR, W. M. J. et.al. Reflexões sobre sentido e significado. In: BOCK, A. M. B.; GONÇALVES, M. das G. M. A dimensão subjetiva da realidade. São Paulo: Cortez, 2009, p. $54-72$.

AGUIAR, W. M. J.; OZELLA, S. Apreensão dos sentidos: aprimorando a proposta dos núcleos de significação. Revista Brasileira de Estudos Pedagógicos. Brasília, v. 94, n. 236, p. 299-322, jan./abr. 2013.

ALMEIDA, L. R. de; PLACCO, V. M. N de S.; SOUZA, V. L. T. de. 0 coordenador pedagógico e a formação de professores: intenções, tensões e contradições. Relatório de pesquisa desenvolvido pela Fundação Carlos Chagas por encomenda da Fundação Victor Civita. Junho, 2011

ANDRÉ, M.; DIAS, H. N. O coordenador pedagógico e a formação de professores para a diversidade. In: ALMEIDA, L. R.; PLACCO, V. M. N. de S. (Orgs.). 0 coordenador pedagógico e o atendimento à diversidade. São Paulo: Loyola, 2010, p. 63-76.

CANDAU, V. M. Formação continuada de professores: tendências atuais. In: CANDAU, V. M. (Org.). Magistério: construção cotidiana. Petrópolis: Vozes, 1997.

CHRISTOV, L. H. da S. Educação continuada: função essencial do coordenador pedagógico. In: GUIMARÃES, A. A. et.al. 0 coordenador pedagógico e a educação continuada. São Paulo: Loyola, 2002, p. 9 - 12.

DAVIS, C . L. F.; NUNES, M. M. R.; ALMEIDA, D. C. A. de. Formação continuada de professores: uma análise das modalidades e das práticas em Estados e Municípios brasileiros. Relatório Final. Pesquisa desenvolvida pela Fundação Carlos Chagas por encomenda da Fundação Victor Civita. Junho, 2011.

ESTEVES, Manuela; RODRIGUES, Ângela. A análise de necessidades na formação de professores. Porto: Porto Editora, 1993. 
LIBÂNEO, J. C. Organização e gestão da escola: teoria e prática. Goiânia: Alternativa, 2004, p. $73-94$.

LIBERALI , F. C. Formação crítica de educadores: questões fundamentais. São Paulo: Pontes Editores, 2010.

LUCÁKS, G. Ontologia do ser social. Os princípios ontológicos fundamentais de Marx. São Paulo: Ciências Humanas, 1979.

MARIN, A. J. Educação continuada: introdução a uma análise de termos e concepções. Caderno CEDES, n. 36. Campinas: UNICAMP, 1995.

MARX, K. ENGELS, F. A ideologia Alemã. Rio de Janeiro: Civilização brasileira, 2006.

NOGUEIRA, M. G. Supervisão Educacional: a questão política. São Paulo: Loyola, 2000.

NÓVOA , A. Formação de professores e profissão docente. In: NÓVOA, Antônio (Coord.). Os professores e sua formação. Lisboa: Dom Quixote, 1995, p. 15-34.

SAVIANI, D. Sobre a natureza e especificidade da educação. Revista Em aberto, Brasília, ano 3, n. 22, jul./ago. 1984.

SMYTH, J. Teacherswork and the politics of reflection. In: América Educational Researche Journal. V. 29, no 2, 1992.

TARDIF, M. Saberes docentes e formação profissional. Petrópolis - RJ: Vozes, 2002.

VIGOTSKI, L. S. Pensamento e Linguagem. São Paulo: Martins Fontes, 2005.

2009.

A construção do pensamento e da linguagem. São Paulo: Martins Fontes,

A formação social da mente. São Paulo: Martins Fontes, 2007.

RECEBIDO: 03/02/2020

APROVADO: 07/04/2020
RECEIVED: 03/02/2020

APPROVED: 07/04/2020
RECIBIDO: 03/02/2020

APROBADO: 07/04/2020 